\title{
Important high light on diabetes in acute coronary syndrome cases: Saudi Arabia
}

\author{
Khalid A. AlNemer* \\ Department of Internal Medicine, Al-Imam Mohammad Ibn Saud Islamic University, Riyadh, Saudi Arabia
}

\begin{abstract}
Diabetes mellitus (DM) patients who present with acute coronary syndrome (ACS) have worse cardiovascular outcomes. We aimed to study clinical features and hospital outcomes of diabetic patients with ACS in Saudi Arabia. This is a review of our retrospective study which included ACS patients enrolled in the Saudi Project for Assessment of Acute Coronary Syndrome (SPACE) study from December 2005 to December 2007, either with DM or newly diagnosed during hospitalization. Baseline demographics, clinical presentation, therapies, and in-hospital outcomes were compared with non-diabetic patients.

Of the 5055 ACS patients enrolled in SPACE, 2929 (58.1\%) had DM (mean age $60.2 \pm 11.5,71.6 \%$ male, and 87.6\% Saudi nationals). Diabetic patients had higher risk-factors (e.g., hypertension, hyperlipidemia) and were more likely to present with non-ST-elevation myocardial infarction $(40.2 \%$ vs. $31.4 \%$, $\mathrm{p}<0.001)$, heart failure ( $25.4 \%$ vs. $13.9 \%, \mathrm{p}<0.001)$, significant left ventricular systolic dysfunction and multi-vessel disease. Diabetic patients had higher in-hospital heart failure, cardiogenic shock, and re-infarction rates. Adjusted odds ratio for in-hospital mortality in diabetic patients was 1.83 (95\% CI, 1.02-3.30, p = 0.042).
\end{abstract}

In conclusion, a substantial proportion of Saudi patients presenting with ACS have DM and a significantly worse prognosis.

\section{Introduction}

The prevalence of diabetes in Saudi Arabia is considered one of the highest in the world at $23.7 \%$ [1]. In addition, the prevalence of diabetes in acute coronary syndrome (ACS) populations is higher in Middle Eastern countries versus other regions [2]. However, there is a lack of data regarding diabetes in Saudi patients presenting with ACS. Thus the objective of our study was to document the risk profile, mode of presentation, therapeutic interventions, and hospital outcomes of diabetic patients presenting with ACS using data from the Saudi Project for Acute Coronary Events (SPACE) registry [3].

\section{Methods}

This was a retrospective study based on the SPACE registry a prospective, multicenter, observational study of all consecutive ACS patients admitted to 17 hospitals in 5 regions of Saudi Arabia; conducted from December 2005 until December 2007 [4].

This study was approved by institutional review boards of all participating hospitals. Demographics, past medical history, provisional diagnosis on admission and final discharge diagnosis, ECG findings, laboratory investigations, medical therapy used on admission during hospitalization and on discharge, use of cardiac procedures and interventions, adverse in-hospital outcomes, and inhospital mortality were collected via case-report forms. Diabetes status was obtained based on self-reporting or the finding from fasting blood sugar test $(>6.9 \mathrm{mmol} / \mathrm{dL})$ upon admission. All statistical analyses were performed using SAS/STAT software.

\section{Results and discussion}

Of the 5055 patients in the SPACE registry; 2929 (57.9\%) were diabetic (92.8\% known diabetics and $7.2 \%$ newly diagnosed). A total of $902(30.8 \%)$ diabetics were on insulin, $1871(63.9 \%)$ on oral hypoglycemic agents, and 156 (5.3\%) followed a diet.

Diabetic patients were older, female, Saudi nationals, had higher risk-factor (e.g., hypertension, hyperlipidemia) prevalence and were more likely to present with non-ST-elevation myocardial infarction (40.2\% vs. $31.4 \%, \mathrm{p}<0.001)$, heart failure $(25.4 \%$ vs. $13.9 \%, \mathrm{p}<0.001)$, significant left ventricular systolic dysfunction and multi-vessel disease.

With regard to hospital pharmacological therapies, no significant differences were detected between diabetic and non-diabetic patients with a few exceptions. The use of angiotensin converting enzyme inhibitors (ACE-I) and angiotensin receptor blockers (ARBs) was greater in the diabetes population. Conversely, diabetic patients with STEMI were less likely to receive thrombolytic therapy $(56.6 \%$ vs. $65 \%$, p < 0.001$)$ (Table 1$)$.

Diabetic patients had higher in-hospital heart failure, cardiogenic shock, and re-infarction rates. Adjusted odds ratio for in-hospital mortality in diabetic patients was 1.83 (95\% CI, 1.02-3.30, p= 0.042) (Figure 1).

The rates of in-hospital mortality, recurrent myocardial infarction, cardiogenic shock, and heart failure were significantly higher among diabetic patients, and diabetic status was an independent predictor for mortality, heart failure, and cardiogenic shock after adjusting for potential confounders [4].

Correspondence to: Khalid A. AlNemer, Department of Internal Medicine, Al-Imam Mohammad Ibn Saud Islamic University, Riyadh, Saudi Arabia, Tel: (00966-1)2037100; Fax: 00966-1-2590209, E-mail: alnemerk@hotmail.com

Key words: diabetes, acute coronary syndrome, cardiovascular outcome, Saudi Arabia

Received: February 24, 2016; Accepted: March 07, 2016; Published: March 09, 2016 
Table 1. Hospital therapies

\begin{tabular}{|c|c|c|c|c|}
\hline Variables & Total & Non-DM & DM & p-Value \\
\hline Aspirin (\%) & $4921(97.76)$ & $2066(97.96)$ & $2855(97.61)$ & 0.402 \\
\hline Clopidogrel (\%) & $4218(83.81)$ & $1755(83.25)$ & $2463(84.21)$ & 0.366 \\
\hline B-blockers (\%) & $4112(81.72)$ & $1724(81.74)$ & $2388(81.70)$ & 0.965 \\
\hline ACEI (\%) & $3500(69.57)$ & $1391(65.96)$ & $2109(72.18)$ & $<0.001$ \\
\hline ARB (\%) & $296(5.91)$ & $96(4.57)$ & $200(6.87)$ & $<0.001$ \\
\hline Statins (\%) & $4698(93.33)$ & $1965(93.17)$ & $2733(93.44)$ & 0.711 \\
\hline Heparin (\%) & $4166(82.64)$ & $1735(82.15)$ & $2431(83)$ & 0.433 \\
\hline GP IIb/ IIIa inhibitors (\%) & $1385(27.47)$ & $588(27.84)$ & $797(27.21)$ & 0.621 \\
\hline Thrombolytics $^{\mathrm{a}}(\%)$ & $1149(60.70)$ & $598(65.00)$ & $551(56.63)$ & $<0.001$ \\
\hline Symptoms onset to hospital arrival time, minutes, median (IQR) & $153(210)$ & $135(204)$ & $173(205)$ & 0.002 \\
\hline DNT, median (IQR) & $53.0(60.0)$ & $50.0(53.0)$ & $60.0(74.0)$ & 0.001 \\
\hline DNT $<30 \min ^{\mathrm{a}}(\%)$ & $142(19.78)$ & $90(22.61)$ & $52(16.25)$ & 0.033 \\
\hline Primary $\mathrm{PCI}^{\mathrm{a}}(\%)$ & $158(17.32)$ & $81(16.49)$ & $77(18.33)$ & 0.46 \\
\hline DBT, median (IQR) & $109.0(68.5)$ & $101.5(47.0)$ & $123.5(85.0)$ & 0.060 \\
\hline PCI $(\%)$ & $1775(35.32)$ & $825(39.14)$ & $950(32.56)$ & $<0.001$ \\
\hline CABG $(\%)$ & $425(8.49)$ & $140(6.66)$ & $285(9.80)$ & $<0.001$ \\
\hline Length of hospital stay, median ( \pm SD) & $5.0(32.33)$ & $4.0(32.92)$ & $5.0(31.98)$ & 0.491 \\
\hline \multicolumn{5}{|c|}{$\begin{array}{l}\text { ACEI angiotensin converting enzyme inhibitors; ARB angiotensinogen receptor blockers; DNT door-to-needle time; PCI percutaneous coronary intervention; DBT door-to-balloon time; } \\
\text { CABG coronary artery bypass grafting. } \\
\text { aProportions were out of STEMI patients receiving reperfusion therapy }\end{array}$} \\
\hline
\end{tabular}

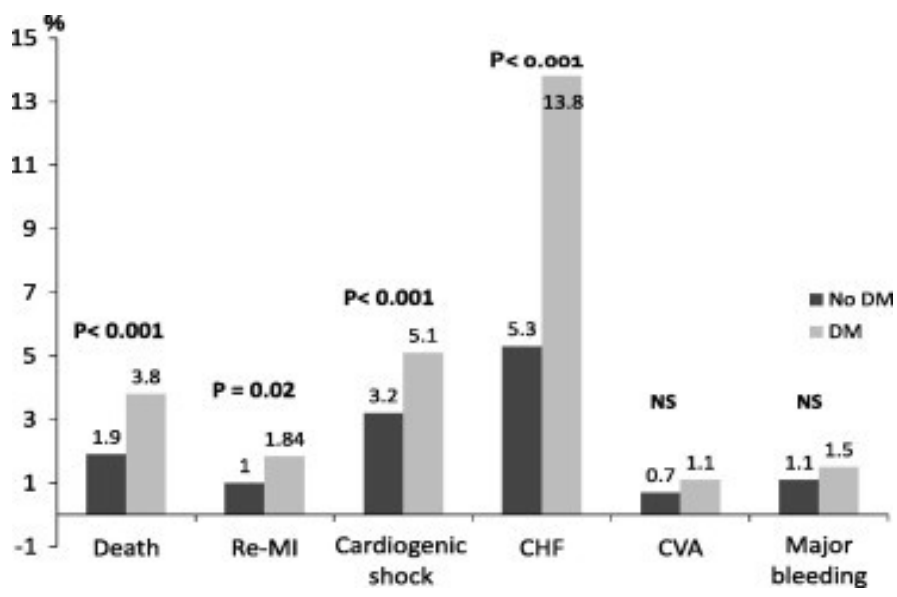

Figure 1. Rates of hospital adverse outcomes in diabetic vs. non-diabetic patients.

\section{Conclusion}

A substantial proportion of Saudi patients presenting with ACS have DM and a significantly worse prognosis. Almost two thirds of ACS patients enrolled in this registry were diabetic, the highest DM prevalence ever reported in an ACS population. This reflects the sedentary lifestyle, adopting the "western diet" and the fast pace of urbanization. Also, the Saudi population has a special genetic predisposition to developing type 2 diabetes; this groundwork is further amplified by a high rate of consanguinity, a rise in obesity rates, and the presence of other components of insulin resistance syndrome. These data highlight the importance of cardiovascular preventative interventions in the general population.

\section{References}

1. Al-Nozha MM, Al-Maatouq MA, Al-Mazrou YY, Al-Harthi SS, Arafah MR, et al (2004) Diabetes mellitus in Saudi Arabia. Saudi Med J 25: 1603-1610. [Crossref]

2. Abdallah MH, Arnaout S, Karrowni W, Dakik HA (2006) The management of acute myocardial infarction in developing countries. Int J Cardiol 111: 189-194. [Crossref]

3. Awad HH, Zubaid M, Alsheikh-Ali AA, Al Suwaidi J, Anderson FA Jr, et al. (2011) Comparison of characteristics, management practices, and outcomes of patients between the global registry and the gulf registry of acute coronary events. Am J Cardiol 108: 1252-1258. [Crossref]

4. AlNemer KA, Alfaleh HF, Alhabib KF, Ullah A, Hersi A, et al. Impact of diabetes on hospital adverse cardiovascular outcomes in acute coronary syndrome patients: Data from the Saudi project of acute coronary events. J Saudi Heart Assoc 24: 225-231. [Crossref]

Copyright: (C2016 AlNemer KA. This is an open-access article distributed under the terms of the Creative Commons Attribution License, which permits unrestricted use, distribution, and reproduction in any medium, provided the original author and source are credited. 